\title{
Dry Flower Disease of Macadamia in Australia Caused by Neopestalotiopsis macadamiae sp. nov. and Pestalotiopsis macadamiae sp. nov.
}

Olufemi A. Akinsanmi, Shaheen Nisa, and Olumide S. Jeff-Ego, The University of Queensland, Centre for Plant Science, Queensland Alliance for Agriculture and Food Innovation, Ecosciences Precinct; Roger G. Shivas, Department of Agriculture and Fisheries, Ecosciences Precinct; and André Drenth, The University of Queensland, Centre for Plant Science, Queensland Alliance for Agriculture and Food Innovation, Ecosciences Precinct, Brisbane, QLD 4001, Australia

\begin{abstract}
Incidence of dry flower disease of macadamia (Macadamia integrifolia), expressed as blight of the flowers and necrosis and dieback of the rachis, is increasing in Australia. In the 2012-13 production season, incidence of dry flower disease resulted in 10 to $30 \%$ yield loss in the affected orchards. Etiology of the disease has not been established. This study was established to characterize the disease and identify the causal pathogen. A survey of the major macadamia-producing regions in Australia revealed dry flower disease symptoms regardless of cultivar or location at all stages of raceme development. Based on colony and conidial morphology, the majority ( $41 \%$ ) of fungal isolates obtained from tissue samples were identified as Pestalotiopsis and Neopestalotiopsis spp. The

phylogeny of the combined partial sequence of the internal transcribed spacer, $\beta$-tubulin, and translation elongation factor $1-\alpha$ gene loci segregated the isolates into two well-supported clades, independent of location or part of the inflorescence affected. Further morphological examination supported the establishment of two new species, which are formally described as Neopestalotiopsis macadamiae sp. nov. and Pestalotiopsis macadamiae sp. nov. Using spore suspensions of isolates of both species, Koch's postulates were fulfilled on three macadamia cultivars at all stages of raceme development. To our knowledge, this is the first report of species of Neopestalotiopsis and Pestalotiopsis as causal agents of inflorescence disease in macadamia.
\end{abstract}

Macadamia (Macadamia integrifolia and M. tetraphylla, along with their hybrids) is grown in commercial plantations in tropical and subtropical frost-free regions worldwide. Macadamia fruit is a dehiscent pericarp (the husk) that encloses a shell and an edible cream-colored kernel (the embryo). Each kernel is derived from one of the six pairs of flowers at each node of the rachis (Trueman and Turnbull 1994). Macadamia flowers are about $15 \mathrm{~mm}$ long, including a 3-mm pedicel (Moncur et al. 1985; Sakai and Mike 1985). Between 100 and 300 flowers are borne on each pendant raceme (inflorescence) and a mature tree may produce over 10,000 racemes (McFadyen et al. 2012; Sedgley 1981; Trueman 2013). In Australia, macadamia raceme elongation starts in mid- to late winter (June to July), with the peak anthesis in late winter or early spring (September) (Heard 1993; Moncur et al. 1985; Trueman and Turnbull 1994; Wallace et al. 1996). Four developmental stages of macadamia raceme (Fitzell 1994) occur during this period. At stage 1, small green florets (or buds) develop on the rachis. At stage 2, the flowers turn light green to white and are partially to fully open and the stamens pull away from the stigmas. At stage 3, the flowers are fully opened for approximately 5 to 10 days and the sepals turn brown. In the final stage, the sepals fall off and the fertilized embryos, still attached to the raceme, begin to swell. Most of the flowers abscise within 2 weeks after fertilization and the remaining fertilized embryos develop rapidly on the rachis, increasing in fruit diameter for up to 15 to 16 weeks after anthesis (McFadyen et al. 2012; Sedgley 1981; Trueman 2013; Trueman and Turnbull 1994; Wallace et al. 1996).

A number of pathogens have been reported to affect macadamia inflorescences, and the diseases they cause are mostly raceme blights (Drenth et al. 2009; Manicom 2003; Zentmyer 1962). There are some distinguishable symptoms of raceme blight caused by different pathogens. Raceme blight or gray mold caused by Botrytis cinerea affects mature flowers at stage 3, with signs of the fungus visible on the senescent flower parts as gray mycelia that hold the collapsed

Corresponding author: O. Akinsanmi; E-mail: uqoakins@uq.edu.au

Accepted for publication 7 September 2016.

C 2017 The American Phytopathological Society flowers together on the rachis. Gray mold has been reported on racemes from most major macadamia-producing countries (Holtzmann 1963; Hunter et al. 1972; Mayers 1993; Nagao and Hirae 1992; Zentmyer 1962). Phytophthora capsici has been reported to cause macadamia flower blight in Costa Rica and Hawaii, where the disease is characterized by extensive and irregular dark necrotic lesions on affected plant parts, including the whole raceme, new leaf flush, young shoots, and immature fruit (Aragaki and Uchida 1980; Kunimoto et al. 1976). Severe raceme blight epidemic, caused by Cladosporium cladosporioides, has been reported from South Africa (van den Berg et al. 2008). Symptoms of raceme blight caused by C. cladosporioides are characterized by small, water-soaked specks on the flower that later become necrotic, with the diseased racemes covered in olive gray patches of mycelia and conidia (van den Berg et al. 2008).

In Australia, a new disease of macadamia racemes, termed dry flower, was first observed in an orchard in the Bundaberg production region in Queensland in 2009. The disease was initially considered a disorder caused by poor tree nutrition, such as phosphorus and boron deficiencies. However, in the 2011-12 production season, the disease resulted in complete crop failure in an orchard and, in the 2012-13 production season, approximately 10 to $30 \%$ yield losses occurred in several orchards in Queensland (Akinsanmi and Drenth 2013). Dry flower disease is increasing in incidence and prevalence in macadamia orchards in Queensland and northern New South Wales (Akinsanmi and Drenth 2013). A preliminary report associated the new disease with Pestalotiopsis spp. (Akinsanmi and Drenth 2013).

Dry flower disease is characterized by the dry appearance of the raceme. Necrotic blight symptoms appear on infected flowers and sometimes on the rachis from early bloom to full anthesis (Fig. 1 A-D). Immature buds or florets may become blighted within a few days, turning brown to dark brown, and remain attached to the green rachis. At later stages of inflorescence development, the floral parts became blighted, while necrotic flower parts may remain attached to the rachis or are easily dislodged when shaken. In certain cases, dried racemes persist in the tree canopy between seasons, and may serve as a source of inoculum in the following season. In some cases, dieback of the rachis at the distal end with advancing necrosis at the tip was seen on diseased racemes.

Dry flower disease poses a threat to macadamia production and, in order to develop and implement effective control measures, it is 
essential to first establish the cause of the disease. The objectives of this study were to (i) identify the causal agent of the disease and fulfill Koch's postulates and (ii) establish the prevalence of the disease. Precise knowledge about the timing of infection, potential sources of inoculum, and disease-conducive environmental factors are important for the development of integrated disease management practices.

\section{Materials and Methods}

Collection of samples and isolates. In order to determine the prevalence and parts of the macadamia inflorescences that were affected, 250 samples, comprising 176 racemes (stage 1), 30 racemes (stage 2), 27 racemes (stage 3), and 17 racemes (stage 4), were collected during a disease survey of commercial macadamia orchards in eastern Australia. Samples were obtained from 10 orchards in Queensland (North, $n=3$; Central, $n=4$; and Southeast, $n=3$ ), as well as 7 orchards in New South Wales (Northern Rivers, $n=5$ and Mid-North coast, $n=2$ ). Both asymptomatic and symptomatic inflorescences with blight symptoms were collected, of which 137 had obvious and distinct raceme blight symptoms. Pieces of tissue were obtained from different sections (distal end, midsection, and basal) of the rachis and flowers from each sample. The pieces were surface sterilized in $2 \%$ sodium hypochlorite solution for $2 \mathrm{~min}$, then rinsed in three changes of sterile distilled water. The tissue was dried using sterile blotting paper before plating on half-strength potato dextrose agar (PDA; Difco Laboratories) plates in four replicates for each sample. The plates were incubated at $25^{\circ} \mathrm{C}$ under a regime of $12 \mathrm{~h}$ of light and $12 \mathrm{~h}$ of darkness for 7 days. The percentage of tissue with fungal growth was recorded from the four replicates. Differences in fungal isolates between locations and among plant parts and sections of racemes were compared by one-way analysis of variance. All fungal colonies were subcultured on fresh PDA plates after 7 days of incubation. Preliminary identity of the fungal isolates was based on cultural and morphological characteristics. Single-spore cultures were derived from selected isolates as described by Akinsanmi et al. (2004) and stored at $-20^{\circ} \mathrm{C}$ in sterile $15 \%$ glycerol solution. Representative isolates were deposited in the Queensland Plant Pathology Herbarium (BRIP), Ecosciences Precinct, Dutton Park, Australia.

DNA extraction and polymerase chain reaction amplification. Genomic DNA of each isolate was extracted from 10-day-old pure cultures using the Promega Wizard Genomic DNA Purification Kit (Promega Corp.), with minor modifications. For each fungal isolate, approximately $40 \mathrm{mg}$ of the mycelium was transferred into a clean 2.0-ml safe-lock tube (Eppendorf AG) containing sterile stainlesssteel beads in $600 \mu \mathrm{l}$ of Nuclei Lysis solution. The content was homogenized using TissueLyser (Qiagen Pty. Ltd.) for 2 min at $30 \mathrm{~Hz}$, before following the DNA extraction procedure in the Wizard Genomic DNA Purification Kit. DNA concentrations were determined using a BioDrop Duo spectrophotometer (BioDrop) and the working stock concentration was adjusted to $25 \mathrm{ng} / \mu \mathrm{l}$. Representative fungal isolates were identified to the genus level based on sequencing of the internal transcribed spacer region (ITS) gene region. Polymerase chain reaction (PCR) amplifications were performed with ITS4 as reverse primer and ITS5 as forward primers, which included the ITS-1, ITS-2, and 5.8S ribosomal RNA gene regions (White et al. 1990).

For isolates tentatively identified as Pestalotiopsis spp. by conidial morphology, partial sequences were amplified of two secondary gene loci; namely, translation elongation factor $1-\alpha$ (TEF) with EF1-728F and EF1-986R primers (Carbone and Kohn 1999) and $\beta$-tubulin (TUB) with primer pairs BT2A and BT2B (Glass and Donaldson 1995; O'Donnell and Cigelnik 1997). PCR amplification was carried out in a $30-\mu \mathrm{l}$ reaction mix as described by Harteveld et al. (2013) using a SuperCycler Thermal Cycler (Kyratec). The PCR program consisted of an initial denaturation step at $98^{\circ} \mathrm{C}$ for $60 \mathrm{~s}$; followed by 35 cycles at $98^{\circ} \mathrm{C}$ for $10 \mathrm{~s}, 62^{\circ} \mathrm{C}$ for $30 \mathrm{~s}$, and $72^{\circ} \mathrm{C}$ for $45 \mathrm{~s}$; and a final extension step at $72^{\circ} \mathrm{C}$ for 5 min.

The PCR amplicons were separated in 1\% agarose gel (BIOLINE) stained with gel red in $0.5 \%$ Tris-borate EDTA buffer solution and viewed under UV light using Molecular Imager GelDoc (Bio-Rad Laboratories Inc.). The amplicon sizes were determined against a 1-kb HyperLadder (BIOLINE) and then the targeted PCR amplicon was purified using Roche High Pure PCR Product Purification Kit (Roche Applied Science) according to the manufacturer's instructions before DNA sequencing with 3730xl DNA analyzer at Macrogen Inc. using the same primers used for amplification.

Phylogenetic analysis. Molecular Evolutionary Genetics Analysis (MEGA6) software (Tamura et al. 2013) was used to manually assemble the forward and reverse sequences into consensus fragments. In order to provide consistency and quality of the sequences, the chromatograms of the sequences were checked and aligned using Clustal W, and primer sequences were trimmed off at both ends of the sequences. For each set of nucleotide sequences, the identity of each isolate was determined by comparison against ex-type cultures available in the National Center for Biotechnology Information GenBank database using the BLAST search procedure. Phylogenetic analyses of the 32 Pestalotiopsis and Neopestalotiopsis isolates (Table 1) were performed by the maximum-parsimony (MP) method in MEGA6 with the concatenated sequences of all the three gene loci (ITS + TUB + TEF), with the selected strains of different species in the phylogenetic clades of the genus Pestalotiopsis, Neopestalotiopsis, and Pseudopestalotiopsis as described by Maharachchikumbura et al. (2014). Sequences of the reference strains were obtained from GenBank (Table 2). The MP phylogram was constructed in MEGA 6 using the Subtree-Pruning-Regrafting algorithm (Nei and Kumar 2000) with search level 1, where the initial trees were obtained by the random addition of sequences. All positions containing gaps and missing data were eliminated. Tree stability was tested

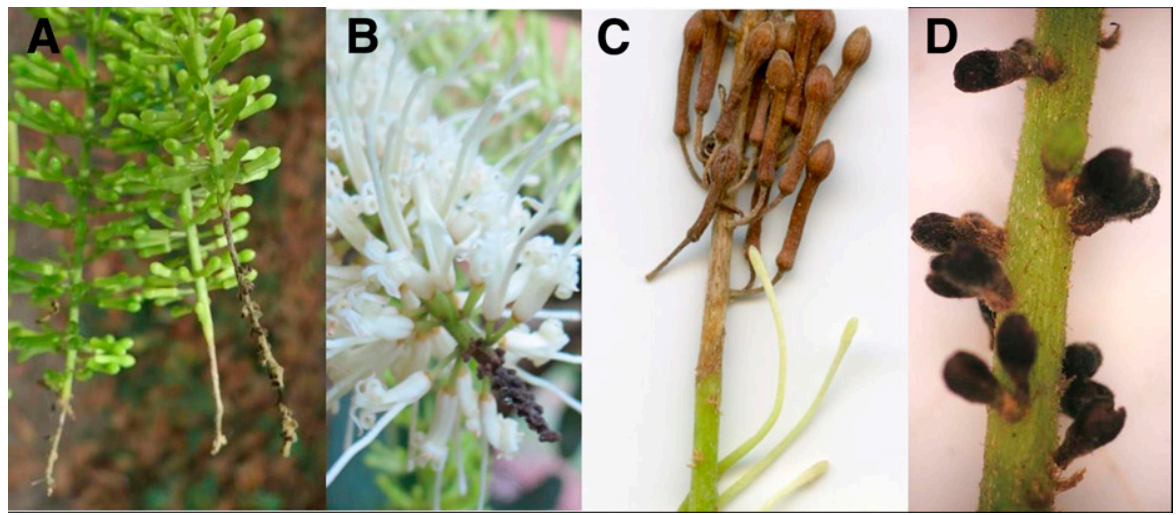

Fig. 1. Symptoms of diseased macadamia racemes associated with species of Pestalotiopsis and Neopestalotiopsis in Australia. A, Macadamia rachis dieback and necrosis; $\mathbf{B}$, rachis dieback; $\mathbf{C}$, flower blight and rachis necrosis at raceme stage 1 developmental period; and $\mathbf{D}$, blight of newly formed flowers. 
by 1,000 bootstrap replicates. All generated sequences were submitted to GenBank.

Morphology. Isolates were grown on $2 \%$ PDA, autoclaved pine needles on water agar, and oat meal agar at $25^{\circ} \mathrm{C}$ under $12 \mathrm{~h}$ of light and $12 \mathrm{~h}$ of darkness for 14 days prior to examination of conidiomata, conidia, and conidiophores under a dissecting microscope and on slide mounts in clear $100 \%$ lactic acid. Fungal structures were viewed and measured at $\times 1,000$ magnification by differential interference contrast using a Leica DM2500 microscope. Conidial sizes were expressed as $95 \%$ confidence levels derived from 20 observations, with extremes of conidial measurements given in parentheses. Colonies were described after 7 days of incubation on PDA using the color charts of Rayner (1970). Novel species were registered in MycoBank (Crous et al. 2004).

Pathogenicity tests. In order to determine the ability of representative fungal isolates to cause disease, pathogenicity was tested on racemes of 'A203' macadamia under field conditions. Spore suspension of each isolate was obtained from 7-day-old culture on PDA, as described previously (Harteveld et al. 2013). A drop of Tween 80 (Sigma-Aldrich) was added to the final spore suspension $\left(10^{5}\right.$ conidia $\left.\mathrm{ml}^{-1}\right)$. Three racemes at each of the three different stages (1 to 3 ) of development on four trees were tested against each isolate. Each raceme was lightly sprayed with the spore suspension until run-off using a spray bottle. Racemes sprayed with sterile distilled water served as negative controls. Inoculated racemes were enclosed for $24 \mathrm{~h}$ at high humidity in moistened polythene bags covered by white paper bags. After $24 \mathrm{~h}$ of incubation, the polythene bags were removed from the paper bags that were left to cover the racemes for 7 to 10 days. Inoculated racemes were removed from the tree and examined for dry flower symptoms. In order to confirm infection and fulfill Koch's postulates, pieces of symptomatic and asymptomatic tissue of the rachis and flowers of each inoculated raceme were surface sterilized and plated on half-strength PDA plates, and the identity of fungal isolates was confirmed as described above. A second set of pathogenicity assays was made with additional isolates of fungi that had successfully infected host material from the first assay. In the second set, three additional isolates, based on the phylogenetic analysis, were included for pathogenicity test on 'HAES 695', A203, and 'HAES 741' macadamia (Table 1).

\section{Results}

Incidence of Pestalotiopsis and Neopestalotiopsis isolates on macadamia racemes. There was no difference in the frequency of Pestalotiopsis and Neopestalotiopsis spp. isolated from the samples obtained from the various locations. Rachis and flowers at stage 1

Table 1. Details of Pestalotiopsis and Neopestalotiopsis isolates obtained from macadamia racemes collected from New South Wales (NSW) and Queensland (QLD) states in Australia included in this study

\begin{tabular}{|c|c|c|c|c|c|c|c|c|}
\hline \multirow[b]{2}{*}{ Species } & \multirow[b]{2}{*}{ BRIPb } & \multirow[b]{2}{*}{ Loc $^{\mathbf{c}}$} & \multirow[b]{2}{*}{$\mathbf{R S}^{\mathbf{d}}$} & \multirow[b]{2}{*}{$\mathbf{P P}^{\mathbf{e}}$} & \multirow[b]{2}{*}{ Symptoms ${ }^{\mathrm{f}}$} & \multicolumn{3}{|c|}{ GenBank accession number ${ }^{\mathrm{a}}$} \\
\hline & & & & & & TUB & ITS & TEF \\
\hline Neopestalotiopsis macadamiae & $63736 a$ & NSW & 3 & FL & FB & KX186651 & KX186601 & KX186623 \\
\hline N. macadamiae & $63736 b^{g}$ & NSW & 3 & FL & FB & KX186652 & KX186603 & KX186625 \\
\hline N. macadamiae & $63737 b$ & NSW & 4 & OV & FB & KX186653 & KX186600 & KX186626 \\
\hline N. macadamiae & $63737 \mathrm{c}^{\mathrm{g}, \mathrm{h}}$ & NSW & 4 & OV & FB & KX186654 & KX186604 & KX186627 \\
\hline N. macadamiae & $63738 \mathrm{a}$ & NSW & 1 & RA & $\mathrm{RD}$ & KX186655 & KX186602 & KX186624 \\
\hline N. macadamiae & $63740 \mathrm{a}^{\mathrm{g}}$ & NSW & 3 & FL & RN, FB & KX186656 & KX186617 & KX186628 \\
\hline N. macadamiae & $63742 \mathrm{a}$ & NSW & 3 & OV & RN, FB & KX186657 & KX186599 & KX186629 \\
\hline N. macadamiae & $63743 a$ & NSW & 2 & FL & RN, FB & KX186658 & KX186598 & KX186631 \\
\hline N. macadamiae & $63744 a$ & QLD & 1 & FL & AF-RD & KX186659 & KX186615 & KX186632 \\
\hline N. macadamiae & $63745 \mathrm{a}$ & QLD & 2 & FL & AF-RD & KX186660 & KX186614 & KX186633 \\
\hline N. macadamiae & $63746 a$ & QLD & 2 & RA & $\mathrm{FB}, \mathrm{RN}, \mathrm{RD}$ & KX186661 & KX186605 & KX186634 \\
\hline N. macadamiae & $63747 \mathrm{a}$ & QLD & 1 & RA & $\mathrm{FB}, \mathrm{RN}, \mathrm{RD}$ & KX186662 & KX186613 & KX186635 \\
\hline N. macadamiae & $63748 \mathrm{a}$ & QLD & 1 & RA & $\mathrm{FB}, \mathrm{RN}, \mathrm{RD}$ & KX186663 & KX186612 & KX186636 \\
\hline N. macadamiae & $63748 b$ & QLD & 1 & RA & $\mathrm{FB}, \mathrm{RN}, \mathrm{RD}$ & KX186664 & KX186611 & KX186637 \\
\hline N. macadamiae & $63749 \mathrm{a}$ & QLD & 1 & RA & $\mathrm{RN}, \mathrm{FB}$ & KX186665 & KX186596 & KX186638 \\
\hline N. macadamiae & $63750 \mathrm{a}$ & QLD & 1 & FL & $\mathrm{RN}$ & KX186666 & KX186610 & KX186639 \\
\hline N. macadamiae & $63751 \mathrm{a}$ & QLD & 1 & FL & $\mathrm{RN}$ & KX186667 & KX186597 & KX186640 \\
\hline N. macadamiae & $63752 a$ & QLD & 2 & RA & $\mathrm{RN}$ & KX186668 & KX186595 & KX186641 \\
\hline N. macadamiae & $63752 b$ & QLD & 2 & RA & $\mathrm{RN}$ & KX186669 & KX186609 & KX186642 \\
\hline N. macadamiae & $63753 a$ & QLD & 2 & RA & $\mathrm{RN}$ & KX186670 & KX186608 & KX186643 \\
\hline N. macadamiae & $63754 a$ & QLD & 4 & OV & FB & KX186671 & KX186606 & KX186644 \\
\hline N. macadamiae & $63755 \mathrm{a}$ & QLD & 1 & RA & $\mathrm{RN}$ & KX186672 & KX186594 & KX186645 \\
\hline N. macadamiae & $63756 a$ & QLD & 3 & RA & $\mathrm{FB}, \mathrm{AR}$ & KX186673 & KX186593 & KX186646 \\
\hline N. macadamiae & $63757 \mathrm{a}$ & QLD & 3 & RA & $\mathrm{FB}, \mathrm{AR}$ & KX186674 & KX186592 & KX186647 \\
\hline N. macadamiae & $63759 \mathrm{a}^{\mathrm{g}}$ & NSW & 1 & RA & $\mathrm{AF}, \mathrm{AR}$ & KX186675 & KX186591 & KX186649 \\
\hline N. macadamiae & $63760 \mathrm{a}^{\mathrm{g}}$ & NSW & 1 & FL & $\mathrm{FB}, \mathrm{RN}, \mathrm{RD}$ & KX186676 & KX186590 & KX186650 \\
\hline Neopestalotiopsis sp. & $63742 b$ & NSW & 3 & OV & $\mathrm{RN}, \mathrm{FB}$ & $\ldots$ & KX186616 & KX186630 \\
\hline Neopestalotiopsis sp. & $63758 \mathrm{a}$ & QLD & 4 & RA & RN & $\ldots$ & KX186607 & KX186648 \\
\hline Pestalotiopsis macadamiae & $63738 b^{g, h}$ & NSW & 1 & RA & $\mathrm{RD}$ & KX186680 & KX186588 & KX186621 \\
\hline P. macadamiae & $63739 \mathrm{a}^{\mathrm{g}}$ & NSW & 1 & RA & $\mathrm{RD}$ & KX186681 & KX186589 & KX186622 \\
\hline P. macadamiae & $63739 b^{g}$ & NSW & 1 & RA & $\mathrm{RD}$ & KX186679 & KX186587 & KX186620 \\
\hline P. macadamiae & $63741 \mathrm{a}^{\mathrm{g}}$ & NSW & 1 & FL & RN, FB & KX186678 & KX186586 & KX186619 \\
\hline Pestalotiopsis sp. & $63737 \mathrm{a}^{\mathrm{g}}$ & NSW & 4 & OV & FB & KX186677 & $\ldots$ & KX186618 \\
\hline
\end{tabular}

\footnotetext{
a Abbreviations: $\beta$-tubulin (TUB), internal transcribed spacer (ITS), and translation elongation factor 1- $\alpha$ (TEF).

b Queensland Plant Pathology Herbarium (BRIP) accession numbers.

${ }^{\mathrm{c}}$ Location.

d Developmental stages of macadamia racemes.

e Plant part: $\mathrm{FL}=$ flower, $\mathrm{OV}=$ ovary, and RA $=$ rachis.

${ }^{\mathrm{f}}$ Symptoms: $\mathrm{FB}=$ flower blight, $\mathrm{RN}=$ rachis necrosis, $\mathrm{RD}=$ rachis dieback, AF-RD = asymptomatic flower but rachis dieback, $\mathrm{AR}=$ asymptomatic rachis, and $\mathrm{AF}=$ asymptomatic flowers

$\mathrm{g}^{\mathrm{g}}$ Isolates used in pathogenicity assays.

${ }^{\mathrm{h}}$ Ex-type cultures. Taxonomic novelties are in bold print.
} 
raceme development were most frequently infected with Pestalotiopsis and Neopestalotiopsis spp. compared with other raceme stages (Fig. 2). Regardless of the raceme stage, flowers at the midsection of the racemes were significantly more frequently infected than those at the distal end (tip) or basal section of the raceme (Fig. 2). In contrast, isolations from rachis at the basal section and distal end were generally more infected with Pestalotiopsis and Neopestalotiopsis spp. than the middle section (Fig. 2).

Pathogenicity assay. In the first series of pathogenicity assays on macadamia A203, both blight and necrotic symptoms were reproduced on racemes inoculated with Pestalotiopsis and Neopestalotiopsis isolates at stages 1 to 3 of raceme development within 7 days after inoculation. No symptoms were produced on racemes inoculated with isolates of Alternaria, Epicoccum, Fusarium, Penicillium, Aspergillus, and Diaporthe and a water control. Collapsed flowers with extensive fungal growth occurred on racemes inoculated with Botrytis and Cladosporium isolates at raceme stage 3 from 7 days after inoculation. Koch's postulates were proven for all the plant materials inoculated with Pestalotiopsis and Neopestalotiopsis isolates. The second series of pathogenicity tests using the additional isolates of Pestalotiopsis and Neopestalotiopsis on different macadamia cultivars showed that isolates from each genus were pathogenic on macadamia racemes, causing raceme blight and necrosis of the rachis on the three cultivars tested.

Identification and classification of fungi. Fungi were recovered from approximately $82 \%$ of the symptomatic and $32 \%$ of the asymptomatic tissues sampled. The percentage of isolates of Pestalotiopsis and Neopestalotiopsis was significantly $(P<0.0001)$ higher than other fungi, which are listed in decreasing order of frequency of isolation as follows: genera Alternaria, Epicoccum, Fusarium, Botrytis, Cladosporium, Penicillium, Aspergillus, and Diaporthe (Fig. 3). The majority (41\%) of the 826 isolates recovered were identified as Pestalotiopsis and Neopestalotiopsis spp. based on their cultural characteristics on quarter-strength PDA and conidial morphology. Species of Pestalotiopsis have four-septate conidia with concolored median cells, whereas Neopestalotiopsis have four-septate conidia with versicolored median cells (Maharachchikumbura et al. 2014).

The MP analyses of the combined sequence data (ITS + TUB + TEF) of the Australian isolates of Pestalotiopsis and Neopestalotiopsis together with reference specimens resulted in phylogenetic trees with the same topology. These trees indicated that Australian isolates of

Table 2. Details of strains representing species in the phylogenetic clades of Pestalotiopsis, Neopestalotiopsis, and closely related genus used in this studya

\begin{tabular}{|c|c|c|c|}
\hline Species & GenBank accession number ${ }^{b}$ & Host family & Location \\
\hline Neopestalotiopsis asiatica & MFLUCC12-0286 & $\ldots$ & China \\
\hline N. australis & CBS 114159 & Proteaceae & Australia \\
\hline N. ellipsospora & MFLUCC12-0283 & $\ldots$ & China \\
\hline N. eucalypticola & CBS 264.37 & Myrtaceae & $\ldots$ \\
\hline N. foedans & CGMCC 3.9123 & $\ldots$ & China \\
\hline N. mesopotamica & CBS 336.86 & Pinaceae & Iraq \\
\hline N. rosae & CBS 101057 & Rosaceae & New Zealand \\
\hline N. surinamensis & CBS 450.74 & $\ldots$ & Suriname \\
\hline Pestalotiopsis arceuthobii & CBS 434.65 & Santalaceae & United States \\
\hline P. arengae & CBS 331.92 & Arecaceae & Singapore \\
\hline P. australasiae & CBS 114126 & Proteaceae & New Zealand \\
\hline P. australis & CBS 114193 & Proteaceae & Australia \\
\hline P. biciliata & CBS 124463 & Platanaceae & $\ldots$ \\
\hline P. chamaeropis & CBS 186.71 & Arecaceae & Italy \\
\hline P. clavata & MFLUCC $12-0268$ & Buxaceae & China \\
\hline P. colombiensis & CBS 118553 & Myrtaceae & Colombia \\
\hline P. diploclisiae & CBS 115587 & Rubiaceae & Hong Kong \\
\hline$P$. diversiseta & MFLUCC12-0287 & Ericaceae & China \\
\hline P. grevilleae & CBS 114127 & Proteaceae & Australia \\
\hline P. hawaiiensis & CBS 114491 & Myrtaceae & United States \\
\hline P. hollandica & CBS 265.33 & Sciadopityaceae & Netherlands \\
\hline P. humus & CBS 336.97 & $\ldots$ & Papua New Guinea \\
\hline P. inflexa & MFLUCC12-0270 & $\ldots$ & China \\
\hline P. intermedia & MFLUCC12-0260 & $\ldots$ & China \\
\hline P. jesteri & CBS 109350 & Gentianaceae & Papua New Guinea \\
\hline P. kenyana & CBS 442.67 & Rubiaceae & Kenya \\
\hline$P$. linearis & MFLUCC12-0272 & Apocynaceae & China \\
\hline P. malayana & CBS 102220 & Euphorbiaceae & Malaysia \\
\hline P. novae-hollandiae & CBS 130973 & Proteaceae & Australia \\
\hline P. oryzae & CBS 353.69 & Poaceae & Denmark \\
\hline P. papuana & CBS 331.96 & $\ldots$ & Papua New Guinea \\
\hline P. parva & CBS 265.37 & Fabaceae & $\ldots$ \\
\hline P. portugalica & CBS 393.48 & $\ldots$ & Portugal \\
\hline P. rosea & MFLUCC 12-0258 & Pinaceae & China \\
\hline P. scoparia & CBS 176.25 & Cupressaceae & $\ldots$ \\
\hline Pestalotiopsis sp. & OP023 & $\ldots$ & $\ldots$ \\
\hline P. spathulata & CBS 356.86 & Proteaceae & Chile \\
\hline P. telopeae & CBS 114161 & Proteaceae & Australia \\
\hline P. trachicarpicola & OP068 & Arecaceae & China \\
\hline P. unicolor & MFLUCC12-0276 & Ericaceae & China \\
\hline Pseudopestalotiopsis cocos & CBS 272.29 & Arecaceae & Indonesia \\
\hline$P$. indica & CBS 459.78 & Malvaceae & India \\
\hline
\end{tabular}

${ }^{a}$ Phylogenetic clades of genus Pestalotiopsis, as described by Maharachchikumbura et al. (2014).

b CBS: culture collection of the Centraalbureau voor Schimmelcultures, Fungal Biodiversity Centre, Utrecht, The Netherlands; CGMCC: China General Microbiological Culture Collection Center, Institute of Microbiology, Chinese Academy of Sciences, Beijing; ICMP: International Collection of Microorganisms from Plants, Auckland, New Zealand; IFRDCC: International Fungal Research \& Development Centre Culture Collection, China; and MFLUCC: Mae Fah Luang University Culture Collection, Chiang Rai, Thailand. 
Pestalotiopsis and Neopestalotiopsis from macadamia formed separate, well-supported clades (Fig. 4). Phylogenetic inference and conidial morphology indicated that these isolates represent two novel species. Most of the isolates belonged to the genus Neopestalotiopsis and there was no association with the part (flower and rachis) from which they were isolated (Table 1).

Taxonomy. Pestalotiopsis macadamiae R. G. Shivas and Akinsanmi, sp. nov. MycoBank MB817931 (Fig. 5). Etymology: Named after the host genus from which it was isolated, Macadamia.

Conidiomata pycnidial in culture on PDA, globose, 200-400 $\mu \mathrm{m}$ diameter, solitary or aggregated in clusters, pale yellow brown, exudes dark brown slimy conidial droplets. Conidiophores septate and sparsely branched or reduced to conidiogenous cells, up to
$40 \mu \mathrm{m}$ long, hyaline, smooth. Conidiogenous cells cylindrical to lageniform, $10-20 \times 2.5-3 \mu \mathrm{m}$, hyaline, smooth. Conidia fusiform to narrowly ellipsoidal, straight or curved, (18-) 18.5-22 (-25) $\times$ (5.5-) 6-6.5 (-7) $\mu \mathrm{m}$, four-septate; apical cell conical, 2.5-5 $\mu \mathrm{m}$ long, hyaline, smooth, thin-walled, with 3 (rarely 2) apical tubular unbranched filiform flexuous appendages (12-) 14-21 (-24) $\mu \mathrm{m}$; basal cell conic with a truncate base, 3-5 $\mu \mathrm{m}$, hyaline to subhyaline, smooth, thin- walled, with a simple appendage 3-7 $\mu \mathrm{m}$ long; three median cells doliiform, 12-15 $\mu \mathrm{m}$, concolored or the lower median cell is slightly paler than the other two cells, olivaceous brown, septa darker than the rest of the cell, smooth, second cell from base 3-6 $\mu \mathrm{m}$ long, third cell 3.5-5 $\mu \mathrm{m}$ long, fourth cell 4-6 $\mu \mathrm{m}$ long.
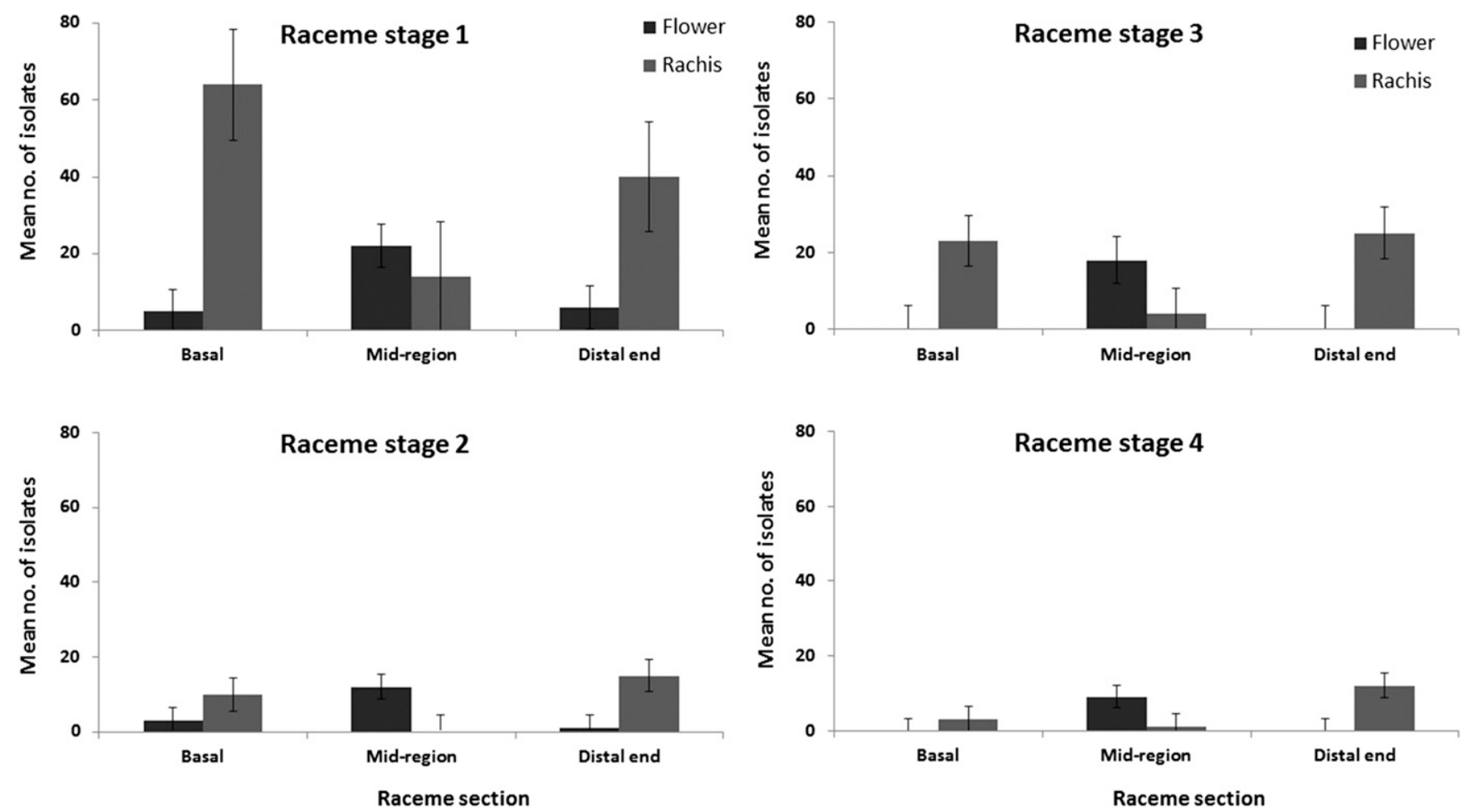

Fig. 2. Mean number of Pestalotiopsis and Neopestalotiopsis isolates recovered from rachis and flowers at different sections of macadamia racemes at the four stages of raceme development. Bars indicate standard error.

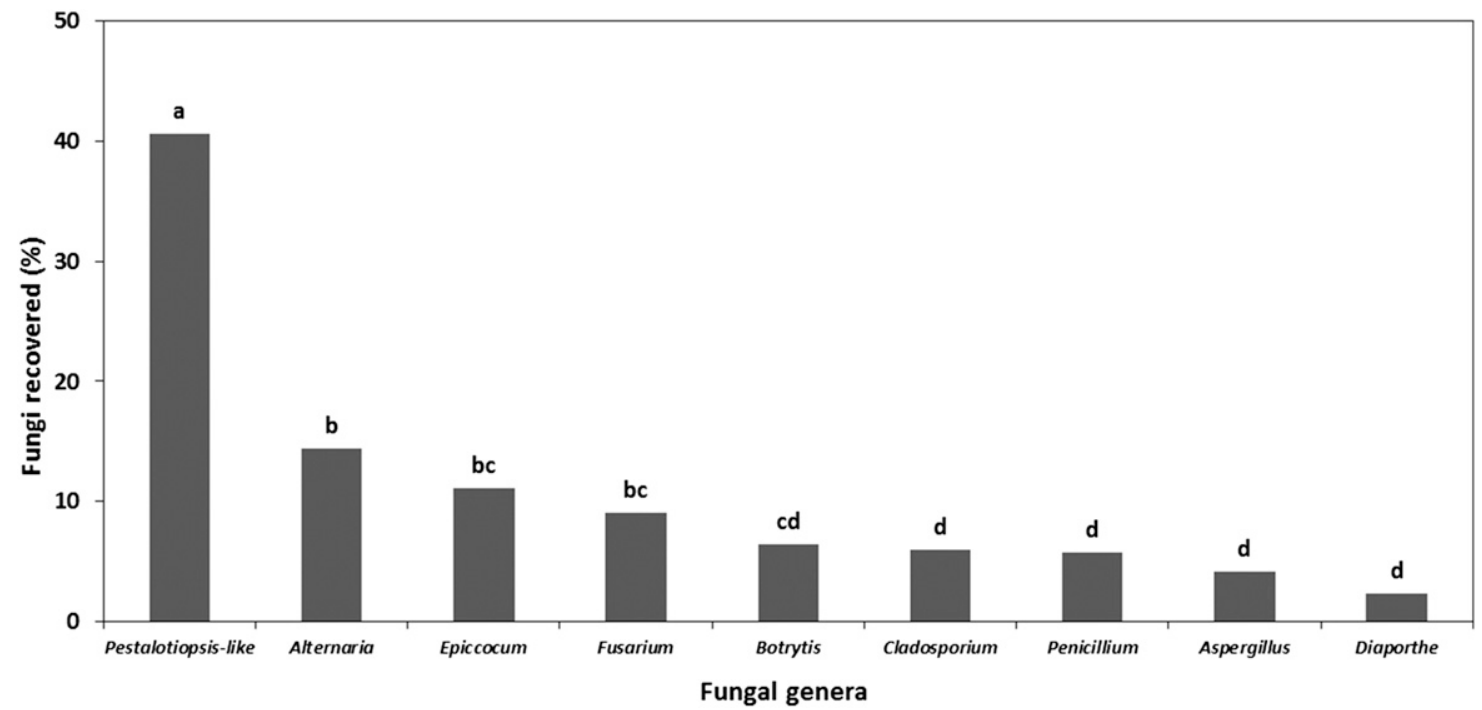

Fig. 3. Percentage of fungi isolated from macadamia racemes collected from different orchards in Australia. Bars with the same letters are not significantly different at $P<0.05$ level according to Fisher's least significant difference test. 
Culture characteristics: Colonies on PDA 6-7 $\mathrm{cm}$ after 7 days at $25^{\circ} \mathrm{C}$, white, margin undulate, aerial mycelium sparse and irregularly zonate, conidiomata black and gregarious in the central $1.5 \mathrm{~cm}$ diameter part, reverse dull white.

Habitat and distribution: Inflorescences of Macadamia integrifolia (Proteaceae); Australia.
Type: AUSTRALIA, New South Wales, Lindendale, on rachis of Macadamia integrifolia with dieback, 20 Aug. 2014, O.A. Akinsanmi, holotype BRIP 63738b, includes ex-type cultures.

Neopestalotiopsis macadamiae R. G. Shivas and Akinsanmi, sp. nov. MycoBank MB817932 (Fig. 6). Etymology: Named after the host genus from which it was isolated, Macadamia.

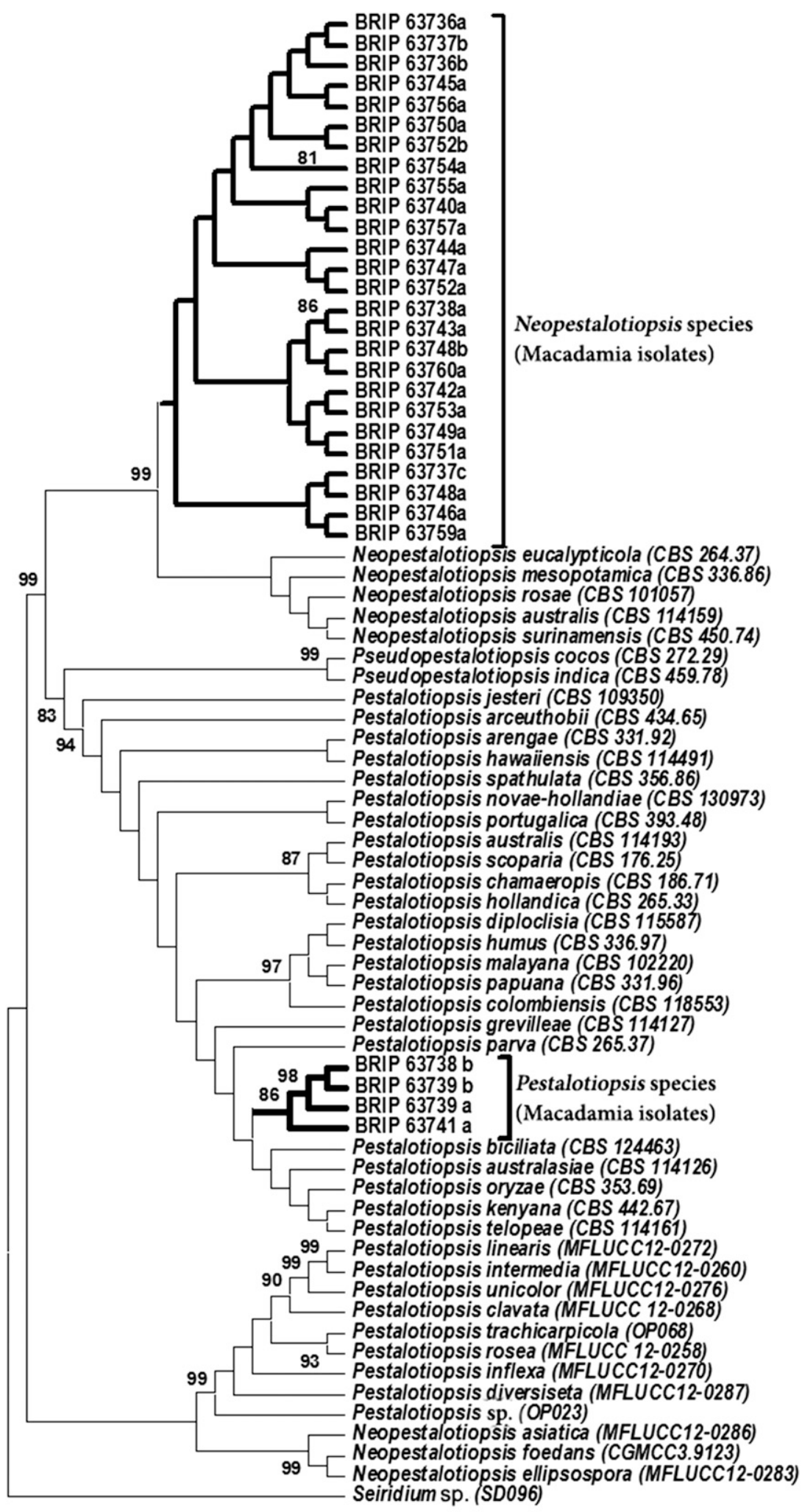

Fig. 4. Maximum-parsimony phylogram of the representative isolates (bold nodes) obtained from macadamia racemes in Australia, with selected strains of different species in the phylogenetic clades of the genera Pestalotiopsis, Neopestalotiopsis, and Pseudopestalotiopsis, as described by Maharachchikumbura et al. (2014). Phylogram is based on more than $50 \%$ majority rule inferred from 1,000 bootstrap replicates generated from combined sequences of internal transcribed spacer, $\beta$-tubulin, and translation elongation factor $1-\alpha$ gene loci, and the bootstrap support values over $80 \%$ are indicated at the nodes. The tree is rooted to Seiridium sp. (SD096). 
Conidiomata pycnidial in culture on PDA, globose, 200-500 $\mu \mathrm{m}$ diameter, solitary or aggregated in clusters, pale yellow brown, exudes dark brown slimy conidial droplets. Conidiophores septate or reduced to conidiogenous cells. Conidiogenous cells ampulliform to cylindrical, 5-20 $\times 2.5-5 \mu \mathrm{m}$, hyaline, smooth. Conidia fusiform to narrowly ellipsoidal, straight or curved, (23-) 24-28 (-29) × (6-) 6.5-7.5 (-8) $\mu \mathrm{m}$, 4-septate; apical cell subcylindrical, 4-6 $\mu \mathrm{m}$ long, hyaline, smooth, thin-walled, with 3 (rarely 2) apical tubular unbranched filiform flexuous appendages (24-) 25-30 (-32) $\mu \mathrm{m}$; basal cell conic with a truncate base, 3-6 $\mu \mathrm{m}$, hyaline, smooth, thin- walled, with a simple appendage 3-7 $\mu \mathrm{m}$ long; three median cells doliiform, 14-18 $\mu \mathrm{m}$, versicolored, olivaceous brown, smooth, septum between median cell and fourth cell from base dark brown and thickened; second cell from base pale brown 3.5-6 $\mu \mathrm{m}$ long, third cell medium to dark brown $4.5-7 \mu \mathrm{m}$ long, fourth cell medium brown 4-6.5 $\mu \mathrm{m}$ long.

Culture characteristics: Colonies on PDA $7-8 \mathrm{~cm}$ after 7 days at $25^{\circ} \mathrm{C}$, white to pale buff, margin entire, mycelium adpressed to very sparse, conidiomata not formed, reverse white to pale buff.

Habitat and distribution: Inflorescences of Macadamia integrifolia (Proteaceae); Australia.

Type: AUSTRALIA, New South Wales, Lindendale, on rachis with dieback of Macadamia integrifolia, 20 Aug. 2014, O.A. Akinsanmi, holotype BRIP 63737c, includes ex-type cultures.

\section{Discussion}

The study characterized a new disease of macadamia racemes in Australia termed dry flower caused by two newly described species,
Pestalotiopsis macadamiae and Neopestalotiopsis macadamiae. Both fungal species were recovered from rachises and flowers of macadamia from different locations in eastern Australia. Various sections of the raceme were infected and $P$. macadamiae and $N$. macadamiae were consistently isolated from flowers with blight symptoms, rachises with necrotic symptoms, and dieback at the distal end of diseased macadamia racemes. To our knowledge, this is the first report of Pestalotiopsis and Neopestalotiopsis spp. as causal agents of raceme blight and rachis dieback in macadamia.

The characteristic symptoms of dry flower disease of macadamia include necrosis or dieback of the rachis (peduncle) tip, and the entire inflorescence (flowers and peduncle) may have dried flowers. All developmental stages of the raceme may be affected, particularly before nut set. Depending on the stage at which infection occurs, dried unopened flowers may remain attached to the rachis, although flowers infected at later stages may dislodge. Sometimes, diseased flowers at an early stage of raceme development cling together by mycelial strands that form on the peduncle. This may be due to secondary fungal colonizers or saprobes on the dead or diseased flowers. A causal relationship between dry flower disease and nut set or yield warrants further study. The key distinguishing characteristics and symptoms of dry flower disease from other raceme blights caused by B. cinerea (Holtzmann 1963) and C. cladosporioides (van den Berg et al. 2008) are the dry appearance of the diseased raceme, infection at all stages of raceme development, and diseased flowers that easily dislodge from the rachises. Koch's postulates were fulfilled with representative isolates P. macadamiae and N. macadamiae, including the ex-type cultures.
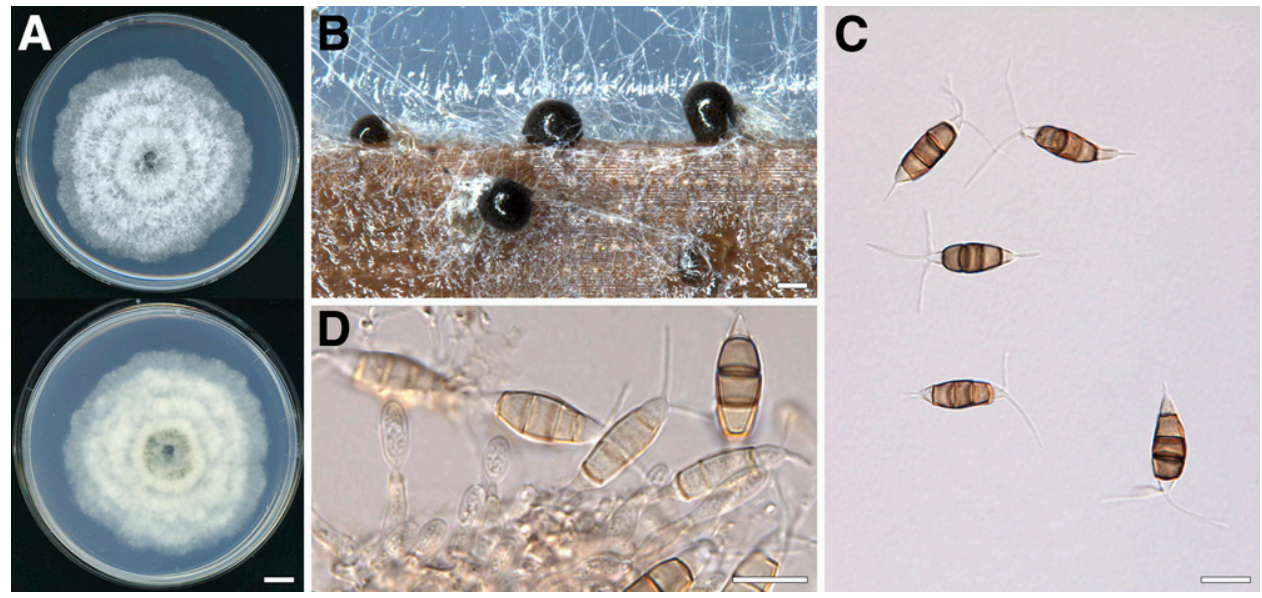

Fig. 5. Pestalotiopsis macadamiae (BRIP 63738b). A, Colony on potato dextrose agar after 7 days at $25^{\circ} \mathrm{C}$ (upper and lower surface); B, conidiomata on pine needle agar; C, conidia; and D, conidiogenous cells. Scale bars: $A=1 \mathrm{~cm}$ and $B$ to $D=10 \mu \mathrm{m}$.
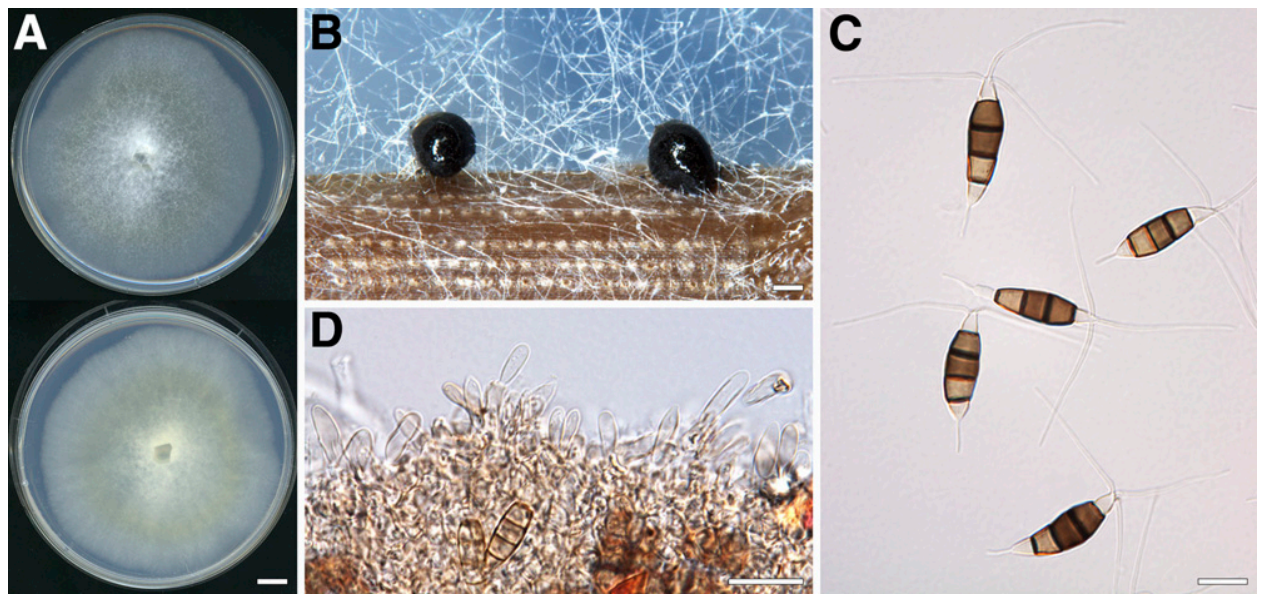

Fig. 6. Neopestalotiopsis macadamiae (BRIP 63738b). A, Colony on potato dextrose agar after 7 days at $25^{\circ} \mathrm{C}$ (upper and lower surface); B, conidiomata on pine needle agar; C, conidia; and D, conidiogenous cells. Scale bars: $A=1 \mathrm{~cm}$ and $B$ to $D=10 \mu \mathrm{m}$. 
Pestalotiopsis and Neopestalotiopsis are relatively important plant pathogenic genera able to infect wide host ranges (Keith et al. 2006; Maharachchikumbura et al. 2011). They are regarded as weak or opportunistic pathogens (Madar et al. 1991) only able to infect wounded or stressed plants (Keith et al. 2006). They are commonly isolated as endophytes (Tejesvi et al. 2009; Wei et al. 2007) and saprobes (Agarwal and Chauhan 1988; Okane et al. 1998; Osono and Takeda 1999). Many Neopestalotiopsis spp. have been isolated as causal agents of leaf spots and tip dieback from several hosts in the Proteaceae family such as macadamia (Maharachchikumbura et al. 2014). Various species of Pestalotiopsis and Neopestalotiopsis have been reported to cause a range of significant diseases in tree nut and fruit crops, including canker of cypress (Madar et al. 1991) and blueberry (Espinoza et al. 2008), leaf spots of Caesalpinia echinata (de Lourdes Mendes and Muchovej 1991) and oil palm (Suwannarach et al. 2013), scab of guava (Keith et al. 2006), shoot dieback of mango (Ismail et al. 2013), blight of Lindera obtusiloba (Jeon et al. 2007) and bayberry (Ren et al. 2013), severe chlorosis or necrotic lesions of maize (Tagne and Mathur 2001), and fruit rots of rambutan and grape (Deng et al. 2013; Keith 2008). In macadamia, $P$. versicolor was associated with leaf spots in India (Rawal and Muniyappa 1981). The genus Pestalotiopsis consists of over 235 described species, most of which are differentiated primarily based on conidial characteristics and traditionally named according to their host associations (Jeewon et al. 2003, 2004; Maharachchikumbura et al. 2011, 2012). The reason why species of Pestalotiopsis that are frequently isolated as endophytes in several horticultural crops are becoming a more common pathogen is still unclear. Anderson et al. (2004) hypothesized that environmental factors may be responsible for causing normally benign fungi to increase in pathogenicity. Species in the genus Pestalotiopsis are known to produce numerous secondary metabolites; however, it is uncertain whether this is associated with the dry appearance of diseased racemes. Although we observed minor variations in disease severity among the isolates and species, the focus of this study was to confirm Koch's postulates of the species; further research is needed to establish and compare aggressiveness between the species on macadamia racemes and also determine whether any variations in aggressiveness are linked to secondary metabolites produced by $P$. macadamiae and $N$. macadamiae.

Further cross-pathogenicity studies are needed to determine whether P. macadamiae and $N$. macadamiae have the potential to cause significant yield losses in other economically important crops. Further studies are currently underway to determine the environmental factors that are conducive for dry flower disease as well as its control in Australia.

\section{Acknowledgments}

The research was funded by Horticulture Innovation Australia Limited with levy funds from the Australian macadamia industry (Project MC12007). We thank C. Searle and several macadamia crop consultants for access to various orchards and samples. This research would not have been possible without their help.

\section{Literature Cited}

Agarwal, A. K., and Chauhan, S. 1988. A new species of the genus Pestalotiopsis from Indian soil. Indian Phytopathol. 41:625-627.

Akinsanmi, O. A., and Drenth, A. 2013. Emergence of Pestalotiopsis species as the causal agent of raceme blight and dieback of macadamia. Page 82 in: 19th Australas. Plant Pathol. Conf. Auckland, New Zealand.

Akinsanmi, O. A., Mitter, V., Simpfendorfer, S., Backhouse, D., and Chakraborty, S. 2004. Identity and pathogenicity of Fusarium spp. isolated from wheat fields in Queensland and northern New South Wales. Aust. J. Agric. Res. 55:97-107.

Anderson, P. K., Cunningham, A. A., Patel, N. G., Morales, F. J., Epstein, P. R., and Daszak, P. 2004. Emerging infectious diseases of plants: Pathogen pollution, climate change and agrotechnology drivers. Trends Ecol. Evol. 19:535-544.

Aragaki, M., and Uchida, J. Y. 1980. Foliar stage of Phytophthora blight of macadamia. Plant Dis. 64:483-484.

Carbone, I., and Kohn, L. M. 1999. A method for designing primer sets for speciation studies in filamentous ascomycetes. Mycologia 91:553-556.

Crous, P. W., Gams, W., Stalpers, J. A., Robert, V., and Stegehuis, G. 2004. MycoBank: an online initiative to launch mycology into the 21st century. Stud. Mycol. 50:19-22.

de Lourdes Mendes, M., and Muchovej, J. J. 1991. Pestalotiopsis leaf spot of Brazil wood, Caesalpinia echinata. Plant Pathol. 40:635-636.
Deng, J. X., Sang, H. K., Hwang, Y. S., Lim, B. S., and Yu, S. H. 2013. Postharvest fruit rot caused by Pestalotiopsis sp. on grape in Korea. Australas. Plant Dis. Notes 8:111-114.

Drenth, A., Akinsanmi, O. A., and Miles, A. K. 2009. Macadamia diseases in Australia. South. Afr. Macadamia Grow. Assoc. Yearb. 17:48-52.

Espinoza, J. G., Briceño, E. X., Keith, L. M., and Latorre, B. A. 2008. Canker and twig dieback of blueberry caused by Pestalotiopsis spp. and a Truncatella sp. in Chile. Plant Dis. 92:1407-1414.

Fitzell, R. D. 1994. Diseases and Disorders of Macadamias. NSW Agriculture, Wollongbar, NSW, Australia.

Glass, N. L., and Donaldson, G. C. 1995. Development of primer sets designed for use with the PCR to amplify conserved genes from filamentous ascomycetes. Appl. Environ. Microbiol. 61:1323-1330.

Harteveld, D. O. C., Akinsanmi, O. A., and Drenth, A. 2013. Multiple Alternaria species groups are associated with leaf blotch and fruit spot diseases of apple in Australia. Plant Pathol. 62:289-297.

Heard, T. A. 1993. Pollinator requirements and flowering patterns of Macadamia integrifolia. Aust. J. Bot. 41:491-497.

Holtzmann, O. V. 1963. Raceme blight of macadamia in Hawaii. Plant Dis. Rep. 47:416-417.

Hunter, J. E., Rohrbach, K. G., and Kunimoto, R. K. 1972. Epidemiology of botrytis blight of macadamia racemes. Phytopathology 62:316-319.

Ismail, A. M., Civrilleri, G., and Polizzi, G. 2013. Characterisation and pathogenicity of Pestalotiopsis uvicola and Pestalotiopsis clavispora causing grey leaf spot of mango (Mangifera indica L.) in Italy. Eur. J. Plant Pathol. 135:619-625.

Jeewon, R., Liew, E. C. Y., and Hyde, K. D. 2004. Phylogenetic evaluation of species nomenclature of Pestalotiopsis in relation to host association. Fungal Divers. 17:39-55

Jeewon, R., Liew, E. C. Y., Simpson, J. A., Hodgkiss, J. I., and Hyde, K. D. 2003. Phylogenetic significance of morphological characters in the taxonomy of Pestalotiopsis species. Mol. Phylogenet. Evol. 27:372-383.

Jeon, Y. H., Kim, S. G., and Kim, Y. H. 2007. First report on leaf blight of Lindera obtusiloba caused by Pestalotiopsis microspora in Korea. Plant Pathol. 56:349.

Keith, L. M. 2008. First report of Pestalotiopsis virgatula causing Pestalotiopsis fruit rot on Rambutan in Hawaii. Plant Dis. 92:835.

Keith, L. M., Velasquez, M. E., and Zee, F. T. 2006. Identification and characterization of Pestalotiopsis spp. causing scab disease of guava, Psidium guajava, in Hawaii. Plant Dis. 90:16-23.

Kunimoto, R. K., Aragaki, M., Hunter, J. E., and Ko, W. H. 1976. Phytophthora capsici, corrected name for the cause of Phytophthora blight of macadamia racemes. Phytopathology 66:546-548.

Madar, Z., Solel, Z., and Kimchi, M. 1991. Pestalotiopsis canker of cypress in Israel. Phytoparasitica 19:79-81.

Maharachchikumbura, S. S. N., Guo, L. D., Cai, L., Chukeatirote, E., Wu, W. P., Sun, X., Crous, P. W., Bhat, D. J., McKenzie, E. H. C., Bahkali, A. H., and Hyde, K. D. 2012. A multi-locus backbone tree for Pestalotiopsis, with a polyphasic characterization of 14 new species. Fungal Divers. 56:95-129.

Maharachchikumbura, S. S. N., Guo, L. D., Chukeatirote, E., Bahkali, A. H., and Hyde, K. D. 2011. Pestalotiopsis-Morphology, phylogeny, biochemistry and diversity. Fungal Divers. 50:167-187.

Maharachchikumbura, S. S. N., Hyde, K. D., Groenewald, J. Z., Xu, J., and Crous, P. W. 2014. Pestalotiopsis revisited. Stud. Mycol. 79:121-186.

Manicom, B. Q. 2003. Macadamia diseases in South Africa. South. Afr Macadamia Grow. Assoc. Yearb. 11:3-7.

Mayers, P. E. 1993. Macadamia nut. Pages 62-65 in: Diseases of Fruit Crops. D. Persley, ed. Queensland Department of Primary Industries, Brisbane, QLD, Australia.

McFadyen, L., Robertson, D., Sedgley, M., Kristiansen, P., and Olesen, T. 2012 Effects of the ethylene inhibitor aminoethoxyvinylglycine (AVG) on fruit abscission and yield on pruned and unpruned macadamia trees. Sci. Hortic. (Amsterdam) 137:125-130

Moncur, M. W., Stephenson, R. A., and Trochoulias, T. 1985. Floral development of Macadamia integrifolia Maiden and Betche under Australian conditions. Sci. Hortic. (Amsterdam) 27:87-96.

Nagao, M. A., and Hirae, H. H. 1992. Macadamia: Cultivation and physiology. Crit. Rev. Plant Sci. 10:441-470.

Nei, M., and Kumar, S. 2000. Molecular Evolution and Phylogenetics. Oxford University Press, New York.

O’Donnell, K., and Cigelnik, E. 1997. Two divergent intragenomic rDNA ITS2 types within a monophyletic linage of the fungus Fusarium are nonorthologous Mol. Phylogenet. Evol. 7:103-116.

Okane, I., Nakagiri, A., and Ito, T. 1998. Endophytic fungi in leaves of ericaceous plants. Can. J. Bot. 76:657-663.

Osono, T., and Takeda, H. 1999. Decomposing ability of interior and surface fungal colonizers of beech leaves with reference to lignin decomposition. Eur. J. Soil Biol. 35:51-56.

Rawal, R. D., and Muniyappa, N. C. 1981. A new leaf disease of macadamia. Curr. Sci. 50:1035.

Rayner, R. W. 1970. A mycological colour chart. CMI and British Mycological Society, Kew, U.K

Ren, H.-Y., Li, G., Qi, X.-J., Fang, L., Wang, H.-R., Wei, J.-G., and Zhong, S 2013. Identification and characterization of Pestalotiopsis spp. causing twig blight disease of bayberry (Myrica rubra Sieb. \& Zucc) in China. Eur. J Plant Pathol. 137:451-461. 
Sakai, W. S., and Mike, A. N. 1985. Fruit growth and abscission in Macadamia integrifolia. Physiol. Plant. 64:455-460.

Sedgley, M. 1981. Early development of the macadamia ovary. Aust. J. Bot. 29: 185-193.

Suwannarach, N., Sujarit, K., Kumla, J., Bussaban, B., and Lumyong, S. 2013. First report of leaf spot disease on oil palm caused by Pestalotiopsis theae in Thailand. J. Gen. Plant Pathol. 79:277-279.

Tagne, A., and Mathur, S. B. 2001. First report of chlorotic spot of maize caused by Pestalotiopsis neglecta. Plant Pathol. 50:791.

Tamura, K., Stecher, G., Peterson, D., Filipski, A., and Kumar, S. 2013. MEGA 6: Molecular Evolutionary Genetics Analysis version 6.0. Mol. Biol. Evol. 30: 2725-2729.

Tejesvi, M. V., Tamhankar, S. A., Kini, K. R., Rao, V. S., and Prakash, H. S. 2009. Phylogenetic analysis of endophytic Pestalotiopsis species from ethnopharmaceutically important medicinal trees. Fungal Divers. 38:167-183.

Trueman, S. J. 2013. The reproductive biology of macadamia. Sci. Hortic. (Amsterdam) 150:354-359.
Trueman, S. J., and Turnbull, C. G. N. 1994. Effects of cross-pollination and flower removal on fruit-set in macadamia. Ann. Bot. (Lond.) 73:23-32.

van den Berg, N., Serfontein, S., Christie, B., and Munro, C. 2008. First report of raceme blight caused by Cladosporium cladosporioides on macadamia nuts in South Africa. Plant Dis. 92:484.

Wallace, H. M., Vithanage, V., and Exley, E. M. 1996. The effect of supplementary pollination on nut set of Macadamia (Proteaceae). Ann. Bot (Lond.) 78:765-773.

Wei, J. G., Xu, T., Guo, L. D., Liu, A. R., Zhang, Y., and Pan, X. H. 2007. Endophytic Pestalotiopsis species associated with plants of Podocarpaceae, Theaceae and Taxaceae in southern China. Fungal Divers. 24:55-74.

White, T. J., Bruns, T., Lee, S., and Taylor, J. 1990. Amplification and direct sequencing of fungal ribosomal RNA genes for phylogenetics. Pages 315-322 in: PCR Protocols. A Guide to Methods and Applications. M. A. Innis, D. H. Gelfand, J. J. Sninsky, and T. J. White, eds. Academic Press, San Diego, CA.

Zentmyer, G. A. 1962. Macadamia diseases in California and Hawaii. Calif Macadamia Soc. Yearb. 8:63-66. 